\title{
Three keys to the radiation of angiosperms into freezing environments
}

\author{
Amy E. Zanne ${ }^{1,2}$, David C. Tank ${ }^{3,4}$, William K. Cornwell ${ }^{5,6}$, Jonathan M. Eastman ${ }^{3,4}$, Stephen A. Smith ${ }^{7}$, Richard G. FitzJohn ${ }^{8,9}$ \\ Daniel J. McGlinn ${ }^{10}$, Brian C. O’Meara ${ }^{11}$, Angela T. Moles ${ }^{6}$, Peter B. Reich ${ }^{12,13}$, Dana L. Royer ${ }^{14}$, Douglas E. Soltis ${ }^{15,16,17}$, \\ Peter F. Stevens ${ }^{18}$, Mark Westoby ${ }^{9}$, Ian J. Wright ${ }^{9}$, Lonnie Aarssen ${ }^{19}$, Robert I. Bertin ${ }^{20}$, Andre Calaminus ${ }^{15}$, Rafaël Govaerts ${ }^{21}$, \\ Frank Hemmings ${ }^{6}$, Michelle R. Leishman ${ }^{9}$, Jacek Oleksyn ${ }^{12,22}$, Pamela S. Soltis ${ }^{16,17}$, Nathan G. Swenson ${ }^{23}$, Laura Warman ${ }^{6,24}$ \\ \& Jeremy M. Beaulieu ${ }^{25}$
}

Early flowering plants are thought to have been woody species restricted to warm habitats ${ }^{1-3}$. This lineage has since radiated into almost every climate, with manifold growth forms ${ }^{4}$. As angiosperms spread and climate changed, they evolved mechanisms to cope with episodic freezing. To explore the evolution of traits underpinning the ability to persist in freezing conditions, we assembled a large species-level database of growth habit (woody or herbaceous; 49,064 species), as well as leaf phenology (evergreen or deciduous), diameter of hydraulic conduits (that is, xylem vessels and tracheids) and climate occupancies (exposure to freezing). To model the evolution of species' traits and climate occupancies, we combined these data with an unparalleled dated molecular phylogeny $(32,223$ species) for land plants. Here we show that woody clades successfully moved into freezingprone environments by either possessing transport networks of small safe conduits ${ }^{5}$ and/or shutting down hydraulic function by dropping leaves during freezing. Herbaceous species largely avoided freezing periods by senescing cheaply constructed aboveground tissue. Growth habit has long been considered labile ${ }^{6}$, but we find that growth habit was less labile than climate occupancy. Additionally, freezing environments were largely filled by lineages that had already become herbs or, when remaining woody, already had small conduits (that is, the trait evolved before the climate occupancy). By contrast, most deciduous woody lineages had an evolutionary shift to seasonally shedding their leaves only after exposure to freezing (that is, the climate occupancy evolved before the trait). For angiosperms to inhabit novel cold environments they had to gain new structural and functional trait solutions; our results suggest that many of these solutions were probably acquired before their foray into the cold.

Flowering plants (angiosperms) today grow in a vast range of environmental conditions, with this breadth probably related to their diverse morphology and physiology ${ }^{7}$. However, early angiosperms are generally thought to have been woody and restricted to warm understory habitats ${ }^{1-3}$. Debate continues about these assertions, in part because of the paucity of fossils and uncertainty in reconstructing habits for these first representatives ${ }^{8-11}$. Nevertheless, greater mechanical strength of woody tissue would have made extended lifespans possible at a height necessary to compete for light ${ }^{12,13}$. A major challenge resulting from increased stature is that hydraulic systems must deliver water at tension to greater heights: as path lengths increase so too does resistance ${ }^{5}$. Among extant strategies, the most efficient method of water delivery is through large-diameter water-conducting conduits (that is, vessels and tracheids) within xylem ${ }^{5}$.

Early in angiosperm evolution they probably evolved larger conduits for water transport, especially compared with their gymnosperm cousins ${ }^{14}$. Although efficient in delivering water, these larger cells would have impeded angiosperm colonization of regions characterized by episodic freezing ${ }^{14,15}$, as the propensity for freezing-induced embolisms (air bubbles produced during freeze/thaw events that block hydraulic pathways) increases as conduit diameter increases ${ }^{5}$. Three evolutionary solutions

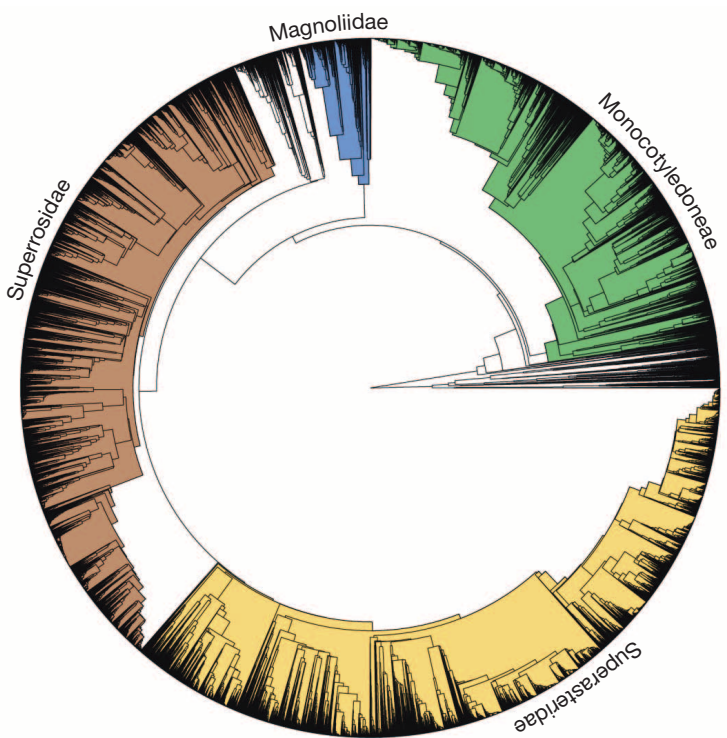

Figure 1 Time-calibrated maximum-likelihood estimate of the molecular phylogeny for 31,749 species of seed plants. The four major angiosperm lineages discussed in the text are highlighted: Monocotyledoneae (green), Magnoliidae (blue), Superrosidae (brown) and Superasteridae (yellow). Non-seed plant outgroups (that is, bryophytes, lycophytes and monilophytes) were removed for the purposes of visualization.

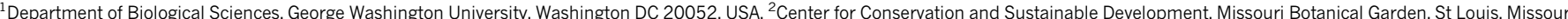

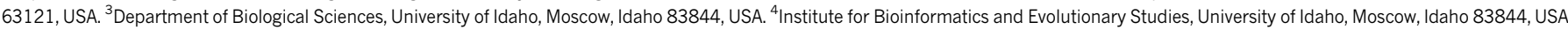

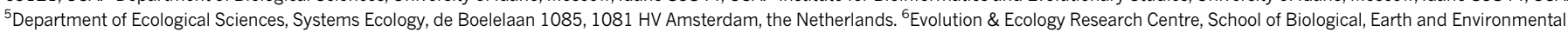
Sciences, University of New South Wales, Sydney, New South Wales 2052, Australia. ${ }^{7}$ Department of Ecology and Evolutionary Biology, University of Michigan, Ann Arbor, Michigan 48109, USA.

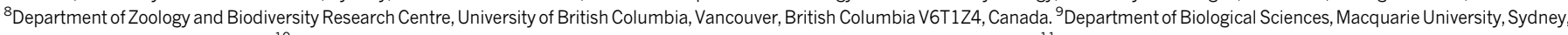
New South Wales 2109, Australia. ${ }^{10}$ Department of Biology and the Ecology Center, Utah State University, Logan, Utah 84322, USA. ${ }^{11}$ Department of Ecology and Evolutionary Biology, University of Tennessee, Knoxville, Tennessee 37996, USA. ${ }^{12}$ Department of Forest Resources, University of Minnesota, St Paul, Minnesota 55108, USA. ${ }^{13}$ Hawkesbury Institute for the Environment, University of

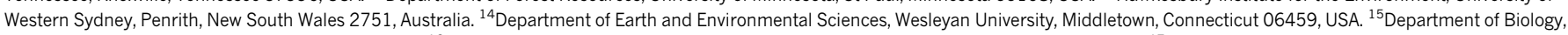

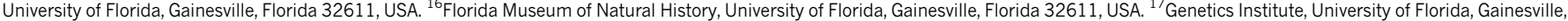
Florida 32611, USA. ${ }^{18}$ Department of Biology, University of Missouri-St Louis, St Louis, Missouri 63121, USA. ${ }^{19}$ Department of Biology, Queen's University, Kingston, Ontario K7L 3N6, Canada.

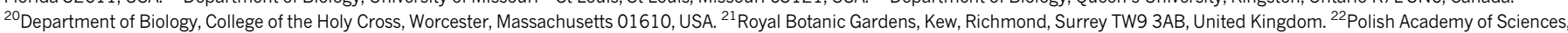

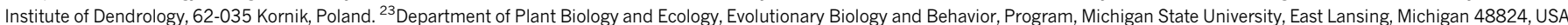

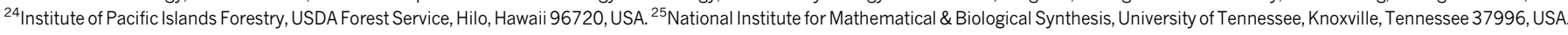


seemingly arose to address the challenges of freezing: (1) woody species withstood freezing temperatures without serious loss of hydraulic function by building safe water-transport networks consisting of small-diameter conduits; (2) woody species shut down hydraulic function by becoming deciduous, dropping leaves during freezing periods; and (3) herbaceous species largely avoided freezing by senescing cheaply constructed aboveground tissue and overwintering, probably as seeds or underground storage organs. However, the order in which angiosperms are likely to have acquired these solutions relative to exposure to and persistence in the cold $^{16}$ remains unclear.

Proportions of herbaceous species, deciduous species and those with small water-conducting conduits increase towards the poles ${ }^{1,4,17,18}$, and an earlier limited survey of angiosperm families indicated that herbaceousness and ability to cope with freezing evolved in paralle ${ }^{19}$. However, exactly how global-scale ecological patterns are linked to functional evolution of angiosperms is uncertain. We dissect the contributions of different evolutionary solutions allowing angiosperms to cope with periodic freezing and assess likely pathways by which clades acquired these traits (that is, timing of evolution in climate occupancy relative to trait evolution).

We compiled a very large species-level database of angiosperm growth habits $\left(49,064\right.$ species, which is $16.4 \%$ of accepted land plant species ${ }^{20}$ in The Plant List; http://www.theplantlist.org), leaf phenology, conduit diameter and freezing climate exposure. To trace species trait and climate occupancy relationships over evolutionary time, we generated an unparalleled time-scaled molecular phylogeny for 32,223 land plant species in our database (Fig. 1; http://www.onezoom.org/vascularplants_tank 2013nature.htm). This timetree gives us the most comprehensive view yet into the evolutionary history of angiosperms. On the basis of their geographic distributions, we classified species' climate occupancies with respect to freezing: 'freezing unexposed', only encountering temperatures
$>0{ }^{\circ} \mathrm{C}$ across a species' range; and 'freezing exposed', encountering temperatures $\leq 0^{\circ} \mathrm{C}$ somewhere across a species' range. This dichotomy assumes that climate tracking through environmental changes is more common than the evolution of climate occupancy; this is more likely to be true if freezing exposure has a physiological cost in regions without freezing ${ }^{21}$. Species were further distinguished by leaf phenology (deciduous or evergreen); conduit diameter (large $\geq 0.044 \mathrm{~mm}$, or small $<0.044 \mathrm{~mm}$; as $0.044 \mathrm{~mm}$ diameter is the diameter above which freezing-induced embolisms are believed to become frequent at modest tensions ${ }^{22}$ ); and growth form (woody or herbaceous, with woody species defined as those maintaining a prominent aboveground stem that is persistent over time and with changing environmental conditions; see Extended Data Fig. 1 for examples of angiosperms with woody growth habits as we define them, and Extended Data Table 1 for a breakdown of growth habit by order within angiosperms).

Among woody species we asked whether evolutionary transitions between climate occupancy states were significantly associated with shifts in leaf phenology and/or conduit diameter. Among all angiosperms we asked whether evolutionary transitions between climate occupancy states were significantly associated with shifts in growth form. We determined the relative lability of climate occupancy (exposure to freezing) versus traits (growth form, leaf phenology or conduit diameter) by summing all climate occupancy transitions and dividing by the sum of all trait transitions. We also devised a novel summary based on these evolutionary transition rates that provides the likeliest pathways from the purported early angiosperm (woody, evergreen, with large conduits and freezing unexposed) to a plant with traits for freezing conditions. Because evolutionary rates are unlikely to be uniform at this phylogenetic scale, we ran growth form analyses both across the entire angiosperm data set and also within each of four major lineages: Monocotyledoneae a

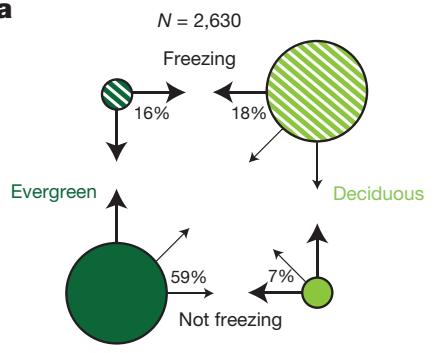

c

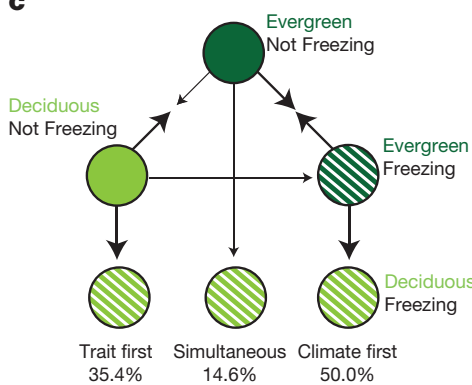

Figure $2 \mid$ Coordinated evolutionary transition rates between leaf phenology or conduit diameter and climate occupancy. a, b, A representation of coordinated evolution for the best likelihood-based model between leaf phenology for 2,630 species (evergreen, dark green; deciduous, light green) and climate occupancy (freezing exposed (freezing), striped; freezing unexposed (not freezing), solid) (a), and conduit diameter for 860 species (large $(\geq 0.044 \mathrm{~mm})$, light blue; small $(<0.044 \mathrm{~mm})$, dark blue) and climate occupancy (b) based on models fit to all Angiospermae. The sizes of the black arrows in the plot are proportional to the transition rates between each possible state combination (larger arrows denote higher rates; no arrows for rates of 0 ). The number at the top of each panel denotes the number of extant Angiospermae species used in the analyses and percentages denote the percentage of extant species with that character state. The size of each circle is proportional to the persistence time in that state, where persistence time is
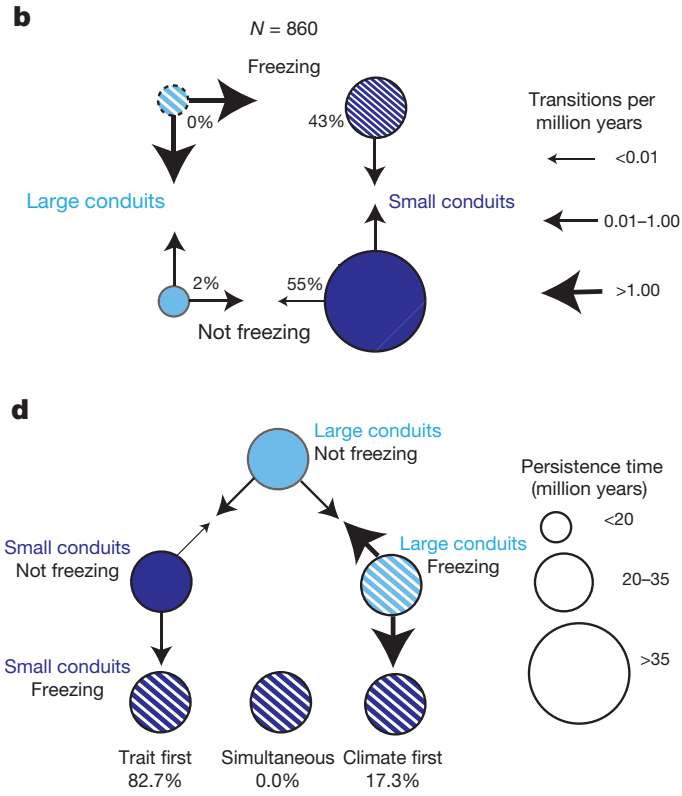

defined as the inverse of the sum of the transition rates away from a given character state (that is, the inverse of the sum of all arrow rates out of a character state). c, d, The relative likelihood of the different pathways out of the evergreen and freezing-unexposed state and into the deciduous and freezing-exposed state (c), and out of the large-diameter conduit and freezing-unexposed state and into the small-diameter conduit and freezing-exposed state (d). The three possible pathways between two focal character state combinations provide insight into whether lineages typically evolved: (1) with the trait first, such that phenology or conduit diameter shifted before encountering freezing; (2) with climate occupancy first, such that phenology or conduit diameter shifted after encountering freezing; or (3) both simultaneously, such that shifts in phenology or conduit diameter and encountering freezing happened at the same time (see Supplementary Information for further details). 
(monocots), Magnoliidae (magnoliids), Superrosidae (superrosids) and Superasteridae (superasterids) (see ref. 10 for lineage definitions); these clades represent $\sim 22 \%, 3 \%, 34 \%$ and $34 \%$, respectively, of all extant angiosperm species.

Across woody angiosperms, a model that assumed coordinated evolution of leaf phenology and climate occupancy was strongly supported over a model that assumed they evolved independently (Akaike information criteria $(\triangle \mathrm{AIC})=310.1$; Fig. $2 \mathrm{a}$ and Extended Data Table 2$)$. Deciduous freezing-exposed and evergreen freezing-unexposed were highly persistent character states (Fig. $2 \mathrm{a}$, as indicated by size of the circles, and Extended Data Table 3); persistence times (that is, expected time until state change) are defined as the inverse of the sum of estimated transition rates away from a given character state. Therefore, in the presence of freezing, the deciduous state was far more stable than the evergreen one. We also found that leaf phenology was generally about as labile as climate occupancy (climate:trait rate ratio $=0.845$ ), and it was also far more likely to evolve as a response to a change in environment rather than arising before encountering freezing (that is, climate occupancy evolved first; Fig. 2c).

Similarly, across woody angiosperms, a model assuming coordinated evolution of conduit diameter size and climate occupancy was strongly supported over a model that assumed they evolved independently $(\triangle \mathrm{AIC}=21.5$; Fig. $2 \mathrm{~b}$ and Extended Data Table 2). Both climate occupancy states (freezing exposed and freezing unexposed) in combination with small conduits were highly persistent (Fig. 2b and Extended Data Table 3). Additionally, no species with large conduits were in the freezing-exposed state, indicating that this is a highly transitory character state (that is, short persistence time). As with leaf phenology, climate occupancy and conduit diameter were similar in their overall lability (climate:trait rate ratio $=0.895$ ); however, a shift into environments with freezing temperatures was far more likely to occur after conduits had already shifted from large to small (that is, the trait evolved before climate occupancy; Fig. 2d).

Evolutionary shifts in growth habit were also strongly coordinated with shifts in climate. However, the nature of coordination varied considerably among major angiosperm clades (Extended Data Table 3), as did overall transition rates (superrosids and superasterids $>$ magnoliids
$>$ monocots). Of 104 models evaluated, a 40-parameter model allowing each major lineage to have its own transition matrix received most support (Extended Data Table 4). These results were generally robust to uncertainty about whether species in the freezing-unexposed state actually lacked an ability to cope with freezing (Supplementary Information). Across angiosperms, asymmetry of transition rates led to numerous extant species in the woody freezing-unexposed and herbaceous freezing-exposed states (Fig. 3a and Extended Data Table 3). The large number of extant species in the woody freezing-unexposed state, according to our model, was the result of this state being persistent (Fig. 3a). Even within monocots, where relatively few woody species exist, the woody freezing-unexposed state was strongly persistent. The herbaceous freezing-exposed state, on the other hand, had low persistence times, indicating that the numerous extant species $(N=4,066$ out of 12,706 species for which data are available) were due to many rapid transitions both into and out of this character state (Fig. 3a). Climate occupancy was much more labile than growth form (climate:trait rate ratio $=4.93$ ). Furthermore, the predominant pathway within angiosperms from the woody freezing-unexposed state to the herbaceous freezing-exposed state was to first evolve the herbaceous habit and subsequently enter habitats with freezing-exposed conditions (that is, the trait evolved before the climate occupancy; Fig. 3b). This, in combination with the conduit diameter results, suggests that lineages that successfully colonized new freezing environments were probably predisposed to do so, at least for these two traits.

Although our focus here is on evolutionary links between species distributions with respect to freezing conditions and traits that allow species to cope with freezing, we note that differential diversification rate $^{23}$ and vagility among lineages also certainly played their parts in determining why we see species where we do today. For instance, herbs may have higher speciation and/or extinction rates than woody taxa ${ }^{24}$. Additionally, growth form may influence a plant's ability to disperse to and colonize newly emerging locations with freezing temperatures ${ }^{25}$. Tests of these alternatives are critical for fully understanding how angiosperms radiated into freezing environments, but such analyses require an even more complete record of global distributions of vagility and growth habit across land plants and a comparably more completely
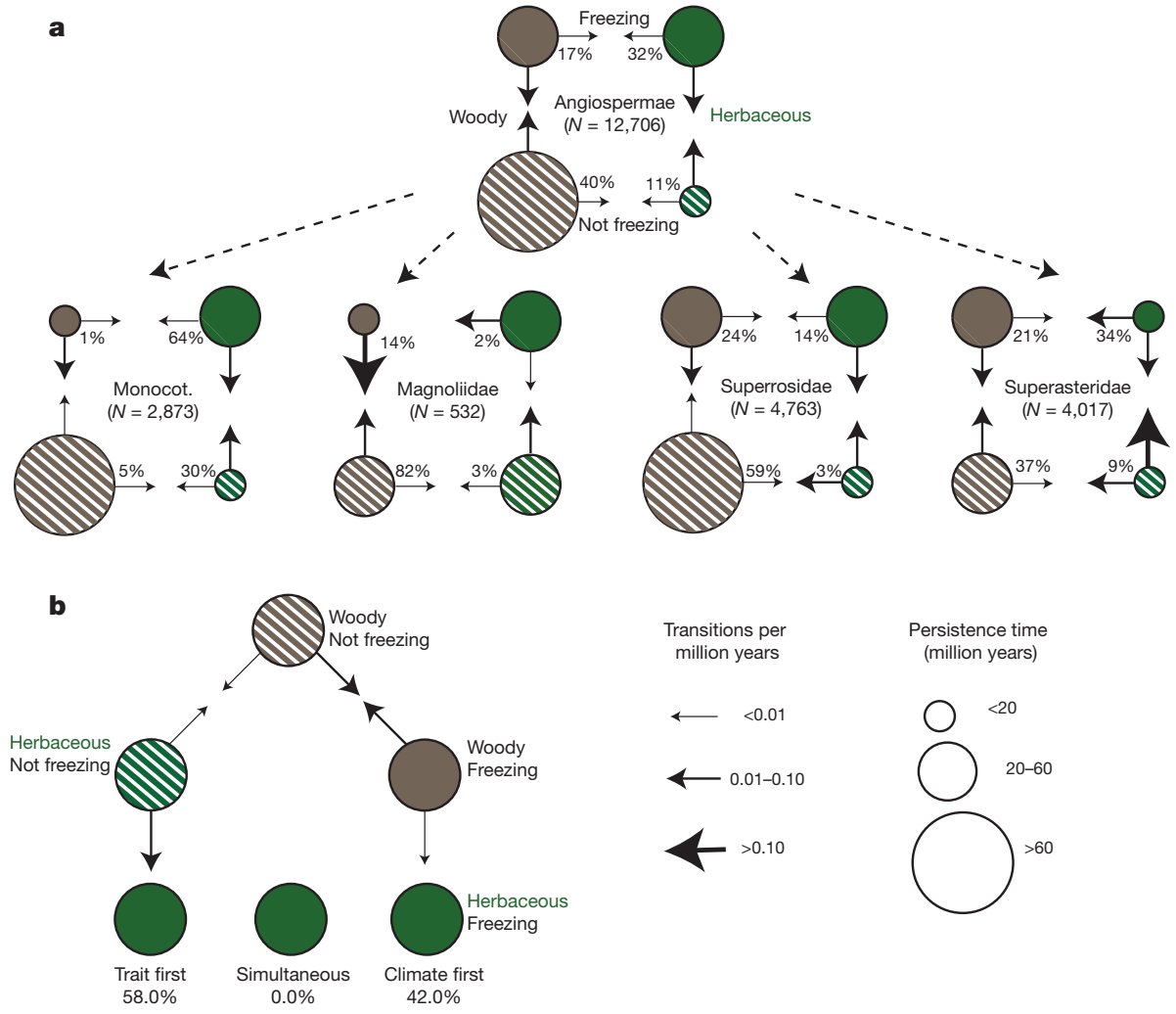

Figure 3 Coordinated evolutionary transition rates between growth form and climate occupancy. a, A representation of coordinated evolution for the best likelihood-based model between growth form for 12,706 species (herbaceous, green; woody, brown) and climate occupancy based on a model assuming the same rates were applied to all Angiospermae (top plot above the dashed arrow), and the best-fit model, in which rates were estimated separately for the major lineages, that is, Monocotyledoneae, Magnoliidae, Superrosidae and Superasteridae (bottom four plots below the dashed arrows). $\mathbf{b}$, The weighted average (by clade diversity) of the relative likelihood of the different pathways out of the woody and freezing-unexposed state and into the herbaceous and freezing-exposed state (see Fig. 2 and Methods for further details). 
sampled phylogeny. These are non-trivial improvements as we currently have growth habit data for only $16 \%$ of accepted land plants ${ }^{20}$ (R.G.F. et al., manuscript submitted) and molecular and climate data for $26 \%$ $(12,706$ species) of those taxa. Total trait records are fewer for phenology (6,705 species) and conduit diameter (2,181 species).

Among three key angiosperm strategies successful in today's freezing environments (deciduous leaves, small conduits and herbaceous habit), our analyses indicated two especially striking findings. First, the pathway to herbaceousness or small conduits in freezing environments largely involved acquisition of the trait first (followed by adaptation to a new climate), whereas the pathway to deciduousness in freezing environments was largely via a shift in climate occupancy first (followed by evolution of the trait). Second, transitions between growth habit states should be fairly simple genetically ${ }^{26}$, involving suppression and re-expression of only a few genes ${ }^{27}$, and, traditionally, growth habit has been considered highly labile (ref. 6 , but see refs 16, 28, 29). Our results are consistent with climate occupancy being more labile than growth habit, and freezing environments being largely filled by a subset of lineages that were already herbaceous or, if woody, had small conduits before they encountered freezing. Why these lineages initially evolved a herbaceous habit and small conduit sizes remains unclear; these traits are probably tightly associated with responses to other environmental gradients (for example, aridity in the tropics) and numerous other aspects of a plant's ecological strategy (for example, seed size, tissue defence, and so on) related to resource acquisition and disturbance regimes. Therefore, successful shifts between stem constructions take more than just turning on or off a few genes.

By weaving together a series of disparate threads encapsulating evolution, functional ecology and the biogeographic history of angiosperms, including extensive functional trait databases and an exceptionally large timetree, we have documented the likely evolutionary pathways of trait acquisition facilitating angiosperm radiation into the cold.

\section{METHODS SUMMARY}

To examine the evolutionary responses to freezing in angiosperms, we first compiled trait data on leaves and stems from existing databases and the literature. Growth form data came from numerous sources and were coded as a binary trait (woody or herbaceous; Supplementary Table 1). Leaf phenology and conduit diameter came from existing databases (see Supplementary Information for a list). Second, taxonomic nomenclature was made consistent among data sets and up to date by querying species names against the International Plant Names Index (http://www.ipni.org/), Tropicos (http://www.tropicos.org/), The Plant List (http:// www.theplantlist.org/) and the Angiosperm Phylogeny website (http://www.mobot. org/MOBOT/research/APweb/). Third, we obtained species' spatial distributions from Global Biodiversity Information Facility records (http://www.gbif.org/; Supplementary Table 4) and then determined whether species encountered freezing temperatures using climate data from the WorldClim database (http://www.worldclim. org/). Fourth, we constructed a dated phylogeny for these species by downloading available GenBank sequences (http://www.ncbi.nlm.nih.gov/genbank/) for seven gene regions. Genetic data were compiled and aligned using the PHLAWD pipeline (v.3.3a), and maximum-likelihood-based phylogenetic analyses of the total sequence alignment were performed using RAxML (v.7.4.1), partitioned by gene region and with major clades (that is, families and orders) constrained according to the APG III classification system. Branch lengths were time-scaled using congruification, which involved using divergence times estimated from a reanalysis of a broadly sampled data set (Extended Data Fig. 2 and Supplementary Tables 2 and 3 ). Last, tests of coordinated evolution among traits in our database were analysed in the corHMM R package; transition rates between two binary traits were analysed using a likelihood-based model.

Online Content Any additional Methods, Extended Data display items and Source Data are available in the online version of the paper; references unique to these sections appear only in the online paper.

Received 3 July; accepted 5 November 2013.

Published online 22 December 2013; corrected online 3 January 2014 (see full-text HTML version for details).

1. Sinnott, E. W. \& Bailey, I. W. The evolution of herbaceous plants and its bearing on certain problems of geology and climatology. J. Geol. 23, 289-306 (1915).
2. Wing, S. L. \& Boucher, L. D. Ecological aspects of the Cretaceous flowering plant radiation. Annu. Rev. Earth Planet. Sci. 26, 379-421 (1998).

3. Feild, T. S., Arens, N. C., Doyle, J. A., Dawson, T. E. \& Donoghue, M. J. Dark and disturbed a new image of early angiosperm ecology. Paleobiology 30, 82-107 (2004).

4. Moles, A. T. et al. Global patterns in plant height. J. Ecol. 97, 923-932 (2009).

5. Tyree, M. T. \& Zimmermann, M. H. Xylem Structure and the Ascent of Sap (Springer, 2002).

6. Cronquist, A. The Evolution and Classification of Flowering Plants. (Houghton Mifflin, 1968).

7. Kattge, J. et al. TRY - a global database of plant traits. Glob. Change Biol. 17, 2905-2935 (2011)

8. Stebbins, G. L. The probable growth habit of the earliest flowering plants. Ann. Mo Bot. Gard. 52, 457-468 (1965).

9. Taylor, D. \& Hickey, L. Phylogenetic evidence for the herbaceous origin of angiosperms. Plant Syst. Evol. 180, 137-156 (1992).

10. Soltis, D. E. et al. Angiosperm phylogeny: 17 genes, 640 taxa. Am. J. Bot. 98, 704-730 (2011)

11. Smith, S. A., Beaulieu, J. M. \& Donoghue, M. J. An uncorrelated relaxed-clock analysis suggests an earlier origin for flowering plants. Proc. Natl Acad. Sci. USA 107, 5897-5902 (2010).

12. Spicer, R. \& Groover, A. Evolution of development of vascular cambia and secondary growth. New Phytol. 186, 577-592 (2010)

13. Feild, T. S. \& Wilson, J. P. Evolutionary voyage of angiosperm vessel structurefunction and its significance for early angiosperm success. Int. J. Plant Sci. 173, 596-609 (2012).

14. Philippe, M. etal. Woody or not woody? Evidence for early angiosperm habit from the Early Cretaceous fossil wood record of Europe. Palaeoworld 17, 142-152 (2008).

15. Wiens, J. J. \& Donoghue, M. J. Historical biogeography, ecology and species richness. Trends Ecol. Evol. 19, 639-644 (2004).

16. Donoghue, M. J. A phylogenetic perspective on the distribution of plant diversity. Proc. Natl Acad. Sci. USA 105, 11549-11555 (2008).

17. Wheeler, E. A., Baas, P. \& Rodgers, S. Variations in dicot wood anatomy: a global analysis based on the Insidewood database. IAWA J. 28, 229-258 (2007)

18. Botta, A., Viovy, N., Ciais, P., Friedlingstein, P. \& Monfray, P. A global prognostic scheme of leaf onset using satellite data. Glob. Change Biol. 6, 709-725 (2000).

19. Judd, W. S., Sanders, R. W. \& Donoghue, M. J. Angiosperm family pairs: preliminary phylogenetic analysis. Harv. Pap. Bot. 5, 1-49 (1994).

20. Paton, A. J. et al. Towards target 1 of the global strategy for plant conservation: a working list of all known plant speciesprogress and prospects. Taxon $\mathbf{5 7 , 6 0 2 - 6 1 1}$ (2008).

21. Loehle, C. Height growth rate tradeoffs determine northern and southern range limits for trees. J. Biogeogr. 25, 735-742 (1998).

22. Davis, S. D. Sperry, J. S. \& Hacke, U. G. The relationship between xylem conduit diameter and cavitation caused by freezing. Am. J. Bot. 86, 1367-1372 (1999).

23. Maddison, W. P. Confounding asymmetries in evolutionary diversification and character change. Evolution 60, 1743-1746 (2006).

24. Soltis, D. E. et al. Phylogenetic relationships and character evolution analysis of Saxifragales using a supermatrix approach. Am. J. Bot. 100, 916-929 (2013).

25. Thomson, F. J., Moles, A. T., Auld, T. D. \& Kingsford, R. T. Seed dispersal distance is more strongly correlated with plant height than with seed mass. J. Ecol. 99, 1299-1307 (2011).

26. Groover,A. T. What genes make a tree a tree? Trends Plant Sci. 10, 210-214 (2005).

27. Lens, F., Smets, E. \& Melzer, S. Stem anatomy supports Arabidopsis thaliana as a model for insular woodiness. New Phytol. 193, 12-17 (2012).

28. Jansson, R., Rodríguez-Castañeda, G. \& Harding, L. E. What can multiple phylogenies say about the latitudinal diversity gradient? A new look at the tropical conservatism, out-of-the-tropics and diversification rate hypotheses. Evolution 67, 1741-1755 (2013).

29. Beaulieu, J. M., O'Meara, B. C. \& Donoghue, M. J. Identifying hidden rate changes in the evolution of a binary morphological character: the evolution of plant habit in campanulid angiosperms. Syst. Biol. 62, 725-737 (2013).

Supplementary Information is available in the online version of the paper.

Acknowledgements We thank T. Robertson and A. Hahn at the Global Biodiversity Information Facility for providing species' georeference points, A. Ordonez for providing growth form data, and A. Miller and D. Ackerly for helpful comments on a draft of this manuscript. Support for this work was given to the working group "Tempo and Mode of Plant Trait Evolution: Synthesizing Data from Extant and Extinct Taxa" by the National Evolutionary Synthesis Center (NESCent), National Science Foundation grant \#EF- 0905606 and Macquarie University Genes to Geoscience Research Centre.

Author Contributions A.E.Z., W.K.C., D.C.T. and J.M.B. designed the initial project, wrote the original manuscript and carried out analyses. J.M.E., S.A.S. and D.C.T. constructed the timetree. J.M.E., R.G.F., D.J.M., B.C.O'M. and S.A.S. were major quantitative contributors, especially with the development of new methods, analyses, graphics and writing. A.T.M., P.B.R., D.L.R., D.E.S., P.F.S., I.J.W. and M.W. were large contributors through the development of initial ideas, methods, dataset curation, analyses and writing. L.A., R.I.B., A.C., R.G., F.H., M.R.L., J.O., P.S.S., N.G.S. and L.W. contributed data sets and discussions, and read drafts.

Author Information Data and code are deposited at the Dryad Digital Repository (http://dx.doi.org/10.5061/dryad.63q27) and TRY (http://www.try-db.org/). Reprints and permissions information is available at www.nature.com/reprints. The authors declare no competing financial interests. Readers are welcome to comment on the online version of the paper. Correspondence and requests for materials should be addressed to A.E.Z. (aezanne@gmail.com). 


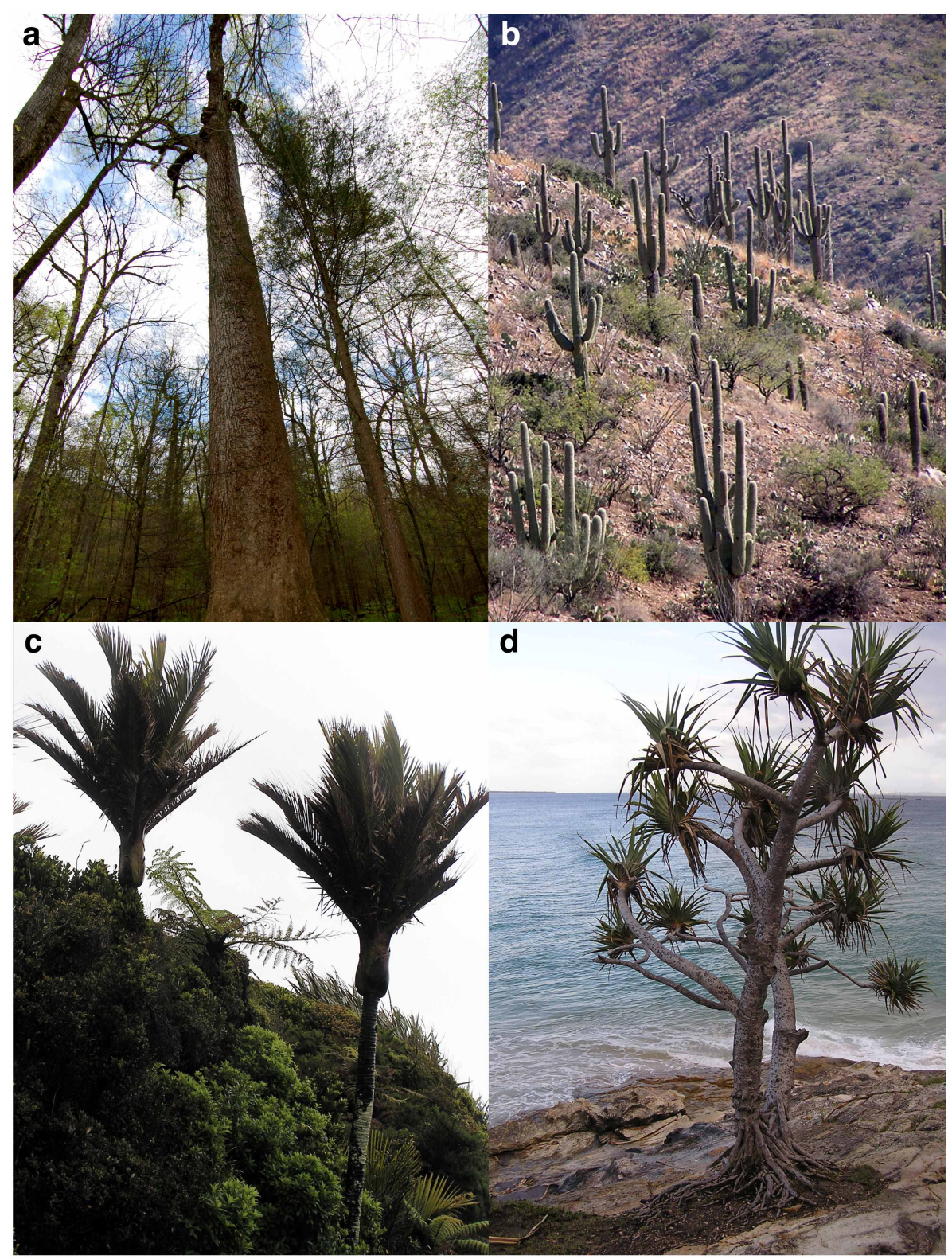

Extended Data Figure $1 \mid$ Examples of the definition of 'woody'. a-d, We defined 'woody' as having a prominent aboveground stem that is persistent over time and with changing environmental conditions. a, Liriodendron tulipifera (Magnoliaceae), Joyce Kilmer Memorial Forest, Robbinsville, North Carolina, USA. b, Carnegiea giganteana (Cactaceae), Biosphere II, Tucson,
Arizona, USA, c, Rhopalostylis sapida (Arecaceae) and Cyathea sp. (Cyatheaceae), Punakaiki, South Island, New Zealand. d, Pandanus sp. (Pandanaceae), Moreton Bay Research Station, North Stradbroke Island, Queensland, Australia (photographs by A.E.Z.). 


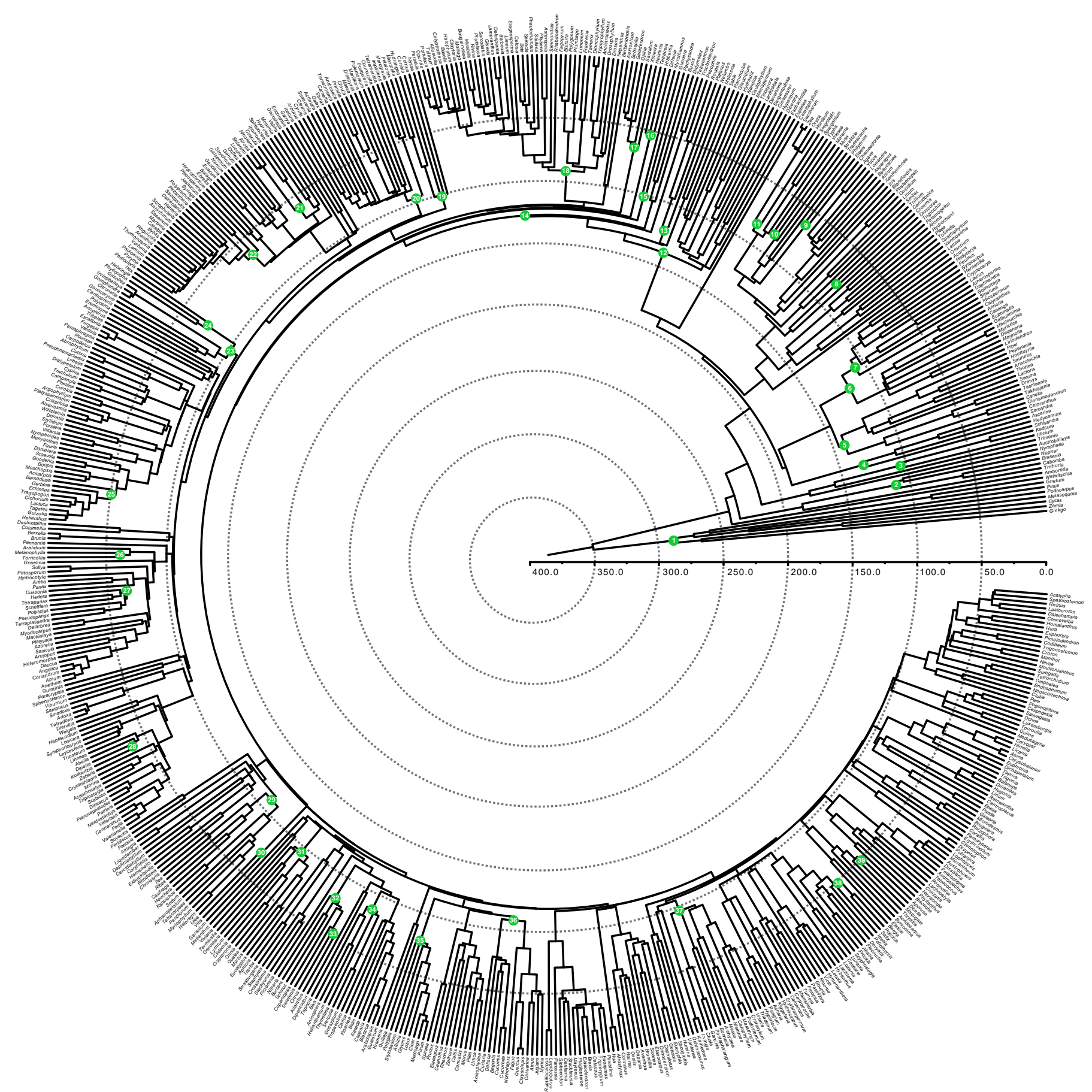

Extended Data Figure $2 \mid$ Reference timetree used for congruification analyses. Results of the divergence time estimation of 639 taxa of seed plants from the reanalysis of a previously described ${ }^{10}$ phylogeny. Fossil calibrations are indicated at the nodes with green circles, and numbers correspond to fossils described in Supplementary Table 2. Concentric dashed circles represent $100-$ Myr intervals as indicated by the scale bar. 
Extended Data Table 1 | Number of species in different growth forms by clade

\begin{tabular}{|c|c|c|c|c|}
\hline Lineage & Woody & Herbaceous & Total & $\begin{array}{c}\text { Proportion } \\
\text { herbaceous }\end{array}$ \\
\hline Angiospermae & 28650 & 17347 & 45997 & 0.38 \\
\hline Magnoliidae & 2438 & 75 & 2513 & 0.03 \\
\hline Monocotyledoneae & 1226 & 9894 & 11120 & 0.89 \\
\hline Superasteridae & 8468 & 4863 & 13331 & 0.36 \\
\hline Superrosidae & 14885 & 1956 & 16841 & 0.12 \\
\hline \multicolumn{5}{|c|}{ ANA grade+Chloranthales } \\
\hline Amborellales & 1 & 0 & 1 & 0.00 \\
\hline Austrobaileyales & 48 & 0 & 48 & 0.00 \\
\hline Chloranthales & 18 & 7 & 25 & 0.28 \\
\hline Nymphaeales & 0 & 43 & 43 & 1.00 \\
\hline \multicolumn{5}{|l|}{ Magnoliidae } \\
\hline Canellales & 71 & 0 & 71 & 0.00 \\
\hline Laurales & 1212 & 6 & 1218 & 0.00 \\
\hline Magnoliales & 1053 & 0 & 1053 & 0.00 \\
\hline Piperales & 102 & 69 & 171 & 0.40 \\
\hline \multicolumn{5}{|l|}{ Monocotyledoneae } \\
\hline Acorales & 0 & 7 & 7 & 1.00 \\
\hline Alismatales & 3 & 513 & 516 & 0.99 \\
\hline Arecales & 793 & 0 & 793 & 0.00 \\
\hline Asparagales & 141 & 4133 & 4274 & 0.97 \\
\hline Commelinales & 0 & 180 & 180 & 1.00 \\
\hline Dioscoreales & 0 & 178 & 178 & 1.00 \\
\hline Liliales & 35 & 459 & 494 & 0.93 \\
\hline Pandanales & 80 & 17 & 97 & 0.18 \\
\hline Petrosaviales & 0 & 3 & 3 & 1.00 \\
\hline Poales & 109 & 4075 & 4184 & 0.97 \\
\hline Zingiberales & 61 & 329 & 390 & 0.84 \\
\hline \multicolumn{5}{|c|}{ Basal eudicots+Gunnerales } \\
\hline Buxales & 31 & 0 & 31 & 0.00 \\
\hline Ceratophyllales & 0 & 3 & 3 & 1.00 \\
\hline Gunnerales & 2 & 14 & 16 & 0.88 \\
\hline Proteales & 1354 & 3 & 1357 & 0.00 \\
\hline Ranunculales & 134 & 488 & 622 & 0.78 \\
\hline Trochodendrales & 2 & 0 & 2 & 0.00 \\
\hline \multicolumn{5}{|l|}{ Superasteridae } \\
\hline Apiales & 410 & 226 & 636 & 0.36 \\
\hline Aquifoliales & 211 & 0 & 211 & 0.00 \\
\hline Asterales & 548 & 1775 & 2323 & 0.76 \\
\hline Berberidopsidales & 3 & 0 & 3 & 0.00 \\
\hline Bruniales & 65 & 0 & 65 & 0.00 \\
\hline Caryophyllales & 545 & 712 & 1257 & 0.57 \\
\hline Cornales & 163 & 68 & 231 & 0.29 \\
\hline Dilleniales & 71 & 0 & 71 & 0.00 \\
\hline Dipsacales & 151 & 61 & 212 & 0.29 \\
\hline Ericales & 2798 & 350 & 3148 & 0.11 \\
\hline Escalloniales & 23 & 0 & 23 & 0.00 \\
\hline Garryales & 17 & 0 & 17 & 0.00 \\
\hline Gentianales & 1508 & 280 & 1788 & 0.16 \\
\hline Lamiales & 1214 & 1035 & 2249 & 0.46 \\
\hline Paracryphiales & 20 & 0 & 20 & 0.00 \\
\hline Santalales & 242 & 20 & 262 & 0.08 \\
\hline Solanales & 254 & 200 & 454 & 0.44 \\
\hline \multicolumn{5}{|l|}{ Superrosidae } \\
\hline Brassicales & 136 & 389 & 525 & 0.74 \\
\hline Celastrales & 228 & 11 & 239 & 0.05 \\
\hline Crossosomatales & 31 & 0 & 31 & 0.00 \\
\hline Cucurbitales & 62 & 169 & 231 & 0.73 \\
\hline Fabales & 2462 & 448 & 2910 & 0.15 \\
\hline Fagales & 745 & 0 & 745 & 0.00 \\
\hline Geraniales & 27 & 63 & 90 & 0.70 \\
\hline Huerteales & 8 & 0 & 8 & 0.00 \\
\hline Malpighiales & 2978 & 294 & 3272 & 0.09 \\
\hline Malvales & 1195 & 64 & 1259 & 0.05 \\
\hline Myrtales & 2787 & 79 & 2866 & 0.03 \\
\hline Oxalidales & 396 & 14 & 410 & 0.03 \\
\hline Picramniales & 16 & 0 & 16 & 0.00 \\
\hline Rosales & 1465 & 143 & 1608 & 0.09 \\
\hline Sapindales & 2082 & 7 & 2089 & 0.00 \\
\hline Saxifragales & 190 & 246 & 436 & 0.56 \\
\hline Vitales & 42 & 1 & 43 & 0.02 \\
\hline Zygophyllales & 35 & 12 & 47 & 0.26 \\
\hline
\end{tabular}




\section{RESEARCH LETTER}

Extended Data Table 2 | Coordinated evolutionary model fits for leaf phenology, conduit diameter and climate occupancy

\begin{tabular}{|c|c|c|c|c|c|}
\hline \multicolumn{6}{|l|}{ Leaf Phenology and climate occupancy } \\
\hline Model & $\begin{array}{l}\text { Number of } \\
\text { parameters }\end{array}$ & $-\ln L$ & AIC & $\triangle \mathrm{AIC}$ & $w_{\mathrm{i}}$ \\
\hline Character independent & 4 & -2305.4 & 4618.9 & 312.8 & $<0.01$ \\
\hline Character dependent, equal rates & 1 & -2401.3 & 4804.5 & 498.4 & $<0.01$ \\
\hline Character dependent, all rates diff & 8 & -2160.0 & 4336.0 & 29.9 & $<0.01$ \\
\hline Character dependent, all rates diff* & 12 & -2141.1 & 4306.1 & 0 & 0.99 \\
\hline \multicolumn{6}{|c|}{ Conduit diameter and climate occupancy } \\
\hline Model & $\begin{array}{l}\text { Number of } \\
\text { parameters }\end{array}$ & $-\ln L$ & $\mathrm{AIC}$ & $\triangle \mathrm{AIC}$ & $w_{i}$ \\
\hline Character independent & 4 & -603.65 & 1223.3 & 21.5 & $<0.01$ \\
\hline Character dependent, equal rates & 1 & -739.8 & 1481.6 & 279.8 & $<0.01$ \\
\hline Character dependent, all rates diff & 8 & -592.91 & 1201.8 & 0 & 0.98 \\
\hline Character dependent, all rates diff* & 12 & -592.91 & 1209.8 & 8.0 & 0.02 \\
\hline
\end{tabular}

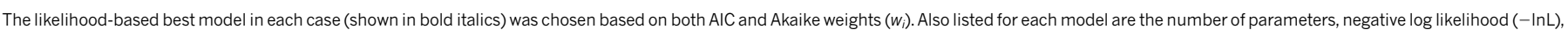
and $\triangle \mathrm{AIC}$. The asterisk indicates a model where simultaneous changes in any two binary characters were allowed to change. 
Extended Data Table 3 | Coordinated evolutionary model transition rates

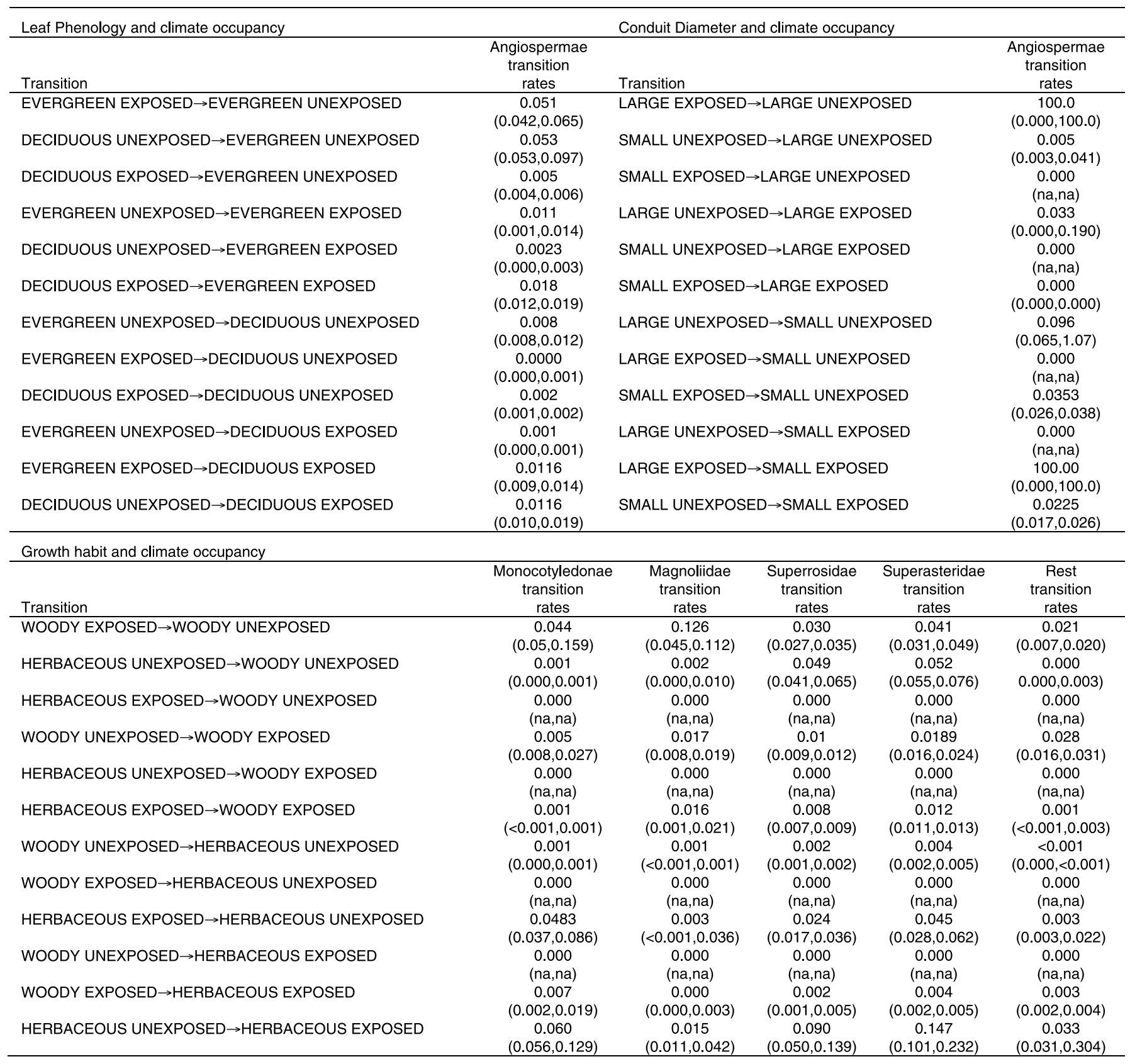

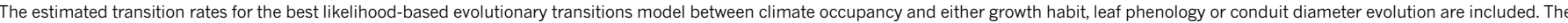

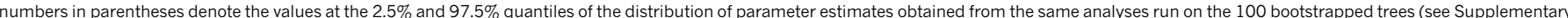

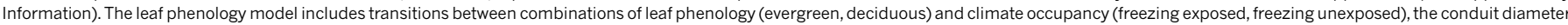

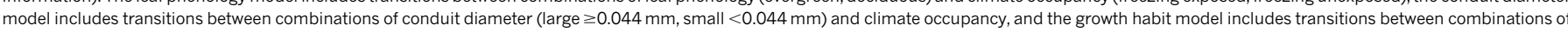
growth form (herbaceous, woody) and climate occupancy. Arrows denote the direction of the transition. The growth habit model assumes separate models for the major groups within angiosperms:

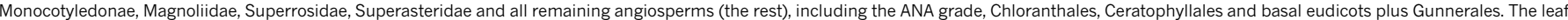
phenology and conduit diameter models assume a single model for all angiosperms. 


\section{RESEARCH LETTER}

Extended Data Table 4 | Coordinated evolutionary model fits for growth form and climate occupancy

\begin{tabular}{lccccc}
\hline Model & Number of parameters & $-\operatorname{lnL}$ & AIC & $\Delta$ AIC & $w_{\mathrm{i}}$ \\
\hline ABCDE & 40 & -8348.9 & 16777.9 & 0 & 0.999 \\
AABCD & $48^{*}$ & -8347.7 & 16791.3 & 13.4 & $<0.001$ \\
AABCD & 32 & -8353.9 & 16794.4 & 16.5 & $<0.001$ \\
\hline
\end{tabular}

The top three of 104 likelihood-based models tested for growth form and climate occupancy evolution are reported. The best model, based on both AIC and Akaike weights $\left(w_{i}\right)$, was a model that assigned a separate rate for the Monocotyledonae (position 1), Magnoliidae (position 2), Superrosidae (position 3), Superasteridae (position 4) and all remaining angiosperms, including the ANA grade, Chloranthales, Ceratophyllales and basal eudicots plus Gunnerales (position 5), respectively. Also listed for each model are the number of parameters, negative log likelihood $(-\operatorname{InL})$, and $\triangle \mathrm{AIC}$. The asterisk indicates a model where simultaneous changes in any two binary characters were allowed. 
CORRIGENDUM

doi:10.1038/nature13842

\section{Corrigendum: Three keys to the radiation of angiosperms into freezing environments}

Amy E. Zanne, David C. Tank, William K. Cornwell, Jonathan M. Eastman, Stephen A. Smith, Richard G. FitzJohn, Daniel J. McGlinn, Brian C. O’Meara, Angela T. Moles, Peter B. Reich, Dana L. Royer, Douglas E. Soltis, Peter F. Stevens, Mark Westoby, Ian J. Wright, Lonnie Aarssen, Robert I. Bertin, Andre Calaminus, Rafaël Govaerts, Frank Hemmings, Michelle R. Leishman, Jacek Oleksyn, Pamela S. Soltis, Nathan G. Swenson, Laura Warman \& Jeremy M. Beaulieu

Nature 506, 89-92 (2014); doi:10.1038/nature12872

In this Letter, Figs 2 and 3 contained several minor errors, which have now been corrected. In Fig. 2c, we did not include the possible pathway from deciduous and freezing unexposed to evergreen and freezing exposed. This omission slightly alters the relative likelihood of the different pathways out of the evergreen and freezing unexposed state $(<2 \%)$, but the interpretation is the same. In Fig. $2 \mathrm{~d}$, we also note that the arrow leading from large conduits and freezing unexposed to large conduits and freezing exposed and the arrow leading from large conduits and freezing exposed to small conduits and freezing exposed were switched when generating the figure. In general, the scale of the circles (persistence times) and arrows (transition rates) in Figs 2 and 3 were also found to be confusing. We have now corrected Figs 2 and 3 online such that the scale matches a discrete binning of the persistence times and transitions rates for each character state combination. We thank E. Edwards for bringing these issues to our attention. Finally, in Extended Data Table 3, we note an incorrect transition rate was provided for the transition from woody unexposed to woody exposed for the Superrosidae; the transition rate should be 0.01 , not 0.001 , and this has also now been corrected online. 


\section{CORRIGENDUM}

doi:10.1038/nature14371

\section{Corrigendum: Three keys to the radiation of angiosperms into freezing environments}

Amy E. Zanne, David C. Tank, William K. Cornwell, Jonathan M. Eastman, Stephen A. Smith, Richard G. FitzJohn, Daniel J. McGlinn, Brian C. O’Meara, Angela T. Moles, Peter B. Reich, Dana L. Royer, Douglas E. Soltis, Peter F. Stevens, Mark Westoby, Ian J. Wright, Lonnie Aarssen, Robert I. Bertin, Andre Calaminus, Rafaël Govaerts, Frank Hemmings, Michelle R. Leishman, Jacek Oleksyn, Pamela S. Soltis, Nathan G. Swenson, Laura Warman \& Jeremy M. Beaulieu

Nature 506, 89-92 (2014); doi:10.1038/nature12872 corrigendum Nature 514, 394 (2014); doi:10.1038/nature 13842

Three readers pointed out that in this Letter we applied the threshold of 0.044 (the size at which freezing-induced embolisms are believed to become frequent at modest tensions) to the area of the conduit (in $\mathrm{mm}^{2}$ ) rather than the diameter (in $\mathrm{mm}$ ). As a consequence, our analysis assumed far too few extant taxa as having a large conduit diameter, which altered the quantitative results considerably for conduit diameter. We now show that (1) the state combination with the largest persistence time is 'large' conduit 'freezing unexposed'; (2) there are fewer transitions out of 'large' conduit 'freezing exposed' than we previously reported owing to many more extant taxa exhibiting this particular state combination; and (3) climate occupancy is more labile than conduit diameter (that is, the ratio of climate to trait is 5.67). Although these quantitative results change for conduit diameter, the interpretation of the possible pathways from 'large' conduit 'freezing unexposed' to 'small' conduit 'freezing exposed' is still qualitatively
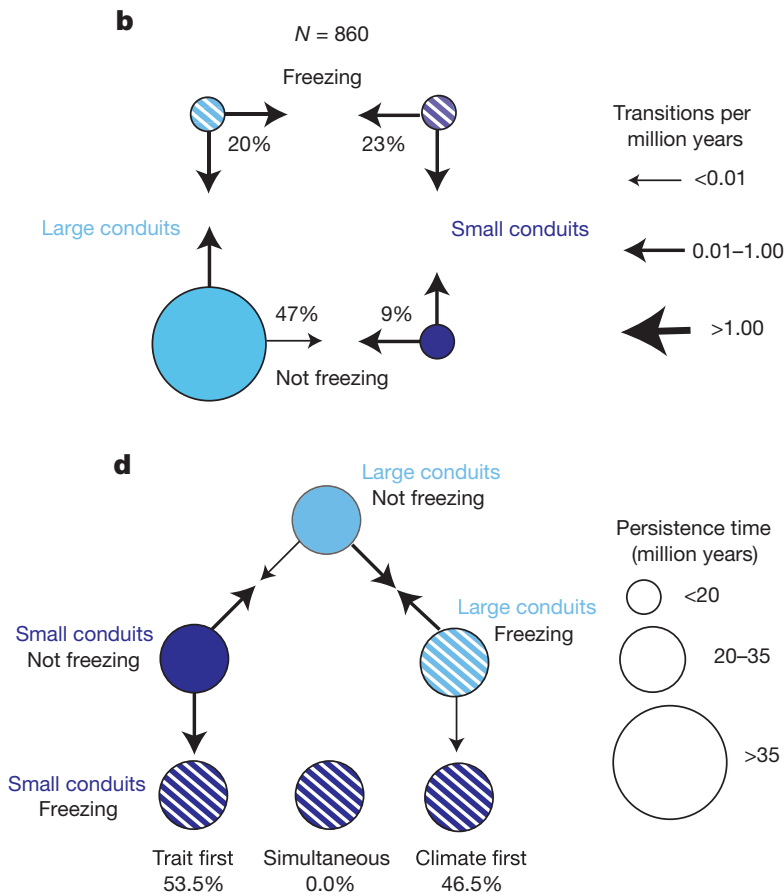

Figure $1 \mid$ This is the corrected Fig. $2 b$ and $d$ of the original Letter. the same at the $0.044-\mathrm{mm}$-diameter threshold. That is, we still find the trait is more likely to evolve prior to a shift in climate occupancy (the trait-first interpretation) at 53.5\%. The trait-first pathway, however, is no longer supported for the secondary 0.030 -mm-diameter threshold reported on page 11 under "Coordinated evolution of growth habit, leaf phenology, and conduit diameter with climate occupancy" of the Supplementary Information of the original Letter.

The original Letter has not been corrected online. Figure 1 of this Corrigendum shows the corrected Fig. $2 b$ and d. The Supplementary Information of this Corrigendum shows the corrected Extended Data Tables 2, 3 and 4 of the original Letter, with updated conduit diameter results in Extended Data Tables 2 and 3 and updated $-\ln L$ for the AABCD model in Extended Data Table 4. Please refer to the corresponding author A.E.Z. for additional details. We thank E. Edwards, J. deVos and M. Donoghue for bringing this issue to our attention.

Supplementary Information is available in the online version of this corrigendum. 